\title{
Time Difference Between the 1854 CE Ansei-Tokai and Ansei-Nankai Earthquakes Estimated from Distant Tsunami Waveforms on the West Coast of North America
}

\section{Satoshi Kusumoto ( $\nabla$ kusumotos@jamstec.go.jp )}

JAMSTEC: Kaiyo Kenkyu Kaihatsu Kiko https://orcid.org/0000-0002-6799-1772

Kentaro Imai

JAMSTEC: Kaiyo Kenkyu Kaihatsu Kiko

Takane Hori

JAMSTEC: Kaiyo Kenkyu Kaihatsu Kiko

\section{Research Article}

Keywords: Historical earthquakes, Historical tsunamis, 1854 CE Ansei-Nankai tsunami, Time difference between Ansei-Tokai and Ansei-Nankai earthquakes, Historical materials, Numerical simulation of trans-Pacific tsunami

Posted Date: September 3rd, 2021

DOl: https://doi.org/10.21203/rs.3.rs-861187/v1

License: (c) (1) This work is licensed under a Creative Commons Attribution 4.0 International License. Read Full License

Version of Record: A version of this preprint was published at Progress in Earth and Planetary Science on January 5th, 2022. See the published version at https://doi.org/10.1186/s40645-021-00458-z. 
1 Time Difference Between the 1854 CE Ansei-Tokai and

2 Ansei-Nankai Earthquakes Estimated from Distant Tsunami

3 Waveforms on the West Coast of North America

4

5 Satoshi Kusumoto ${ }^{1}$

6 Corresponding author

$7 \quad$ Email: kusumotos@jamstec.go.jp

8

$9 \quad$ Kentaro Imai ${ }^{1}$

10 Email: imaik@jamstec.go.jp

Takane Hori ${ }^{1}$

Email: horit@jamstec.go.jp

${ }^{1}$ Research Institute for Marine Geodynamics, Research and Development Center for Earthquake and 


\section{Abstract}

We estimated the time difference between the 1854 CE Ansei-Tokai and Ansei-Nankai

earthquakes from tidal records of two tide gauge stations (San Francisco and San Diego) on the west coast of North America. The first signals of the Ansei-Tokai tsunami were apparent, whereas those of the Ansei-Nankai tsunami were obscured by the later waves of the Ansei-Tokai tsunami. Waveforms of the Ansei-Nankai tsunami simulated with non-linear dispersive wave theory by assuming an origin time of 07:00 GMT on 24 December arrived earlier than in the observations. The normalized root mean square and the misfit between the simulated and observed waveforms of the Ansei-Nankai tsunami showed a time difference between them of approximately $0.4 \mathrm{~h}$. This finding suggests that the actual origin time of the Ansei-Nankai tsunami was approximately 07:24 GMT on 24 December. A previous study estimated the origin time of the Ansei-Tokai tsunami to be about 00:30 GMT on 23 December. Thus, we concluded that the time difference between the 1854 CE Ansei-Tokai and AnseiNankai tsunamis was $30.9 \mathrm{~h}$. Despite the significant difference in the time resolution between the seasonal timekeeping system used in Japan in 1854 and waveform digitization, our result is roughly effectively used to determine the origin times of historical earthquakes. 


\section{Keywords}

40 Historical earthquakes, Historical tsunamis, 1854 CE Ansei-Nankai tsunami, Time difference between

41 Ansei-Tokai and Ansei-Nankai earthquakes, Historical materials, Numerical simulation of trans-

$42 \quad$ Pacific tsunami

43

\section{Introduction}

The Nankai Trough subduction zone has repeatedly generated large earthquakes accompanied by tsunamis (e.g., Ando, 1975; Ishibashi, 2004). The fault region has been divided into six segments (e.g.,

47 Garrett et al., 2016; Fujiwara et al., 2020), and two main rupture patterns are observed: in the first, all segments rupture simultaneously, whereas in the second, different segments rupture at different times, with a time lag between ruptures of a few hours to years. The 1707 CE Hoei Nankai earthquake is an example of the first pattern, whereas the 1854 CE Ansei-Tokai and Ansei-Nankai earthquakes and the 1944 CE Showa-Tonankai and 1946 CE Showa-Nankai earthquakes are examples of the second pattern. The 1944 CE and 1946 CE events occurred about two years apart (e.g., Imai et al., 2006), and the two 1854 events approximately 30-32 h apart (e.g., Usami, 2003; Central Disaster Management

54 Council, 2005; Matsu'ura, 2017). Thus, Nankai Trough megathrust earthquakes exhibit diverse behaviors. 

of these earthquakes generated huge tsunamis. In this study, we focused on the time difference between the 1854 CE Ansei-Tokai and Ansei-Nankai earthquakes. In 1854, a seasonal time system was used in Japan; the day and night were separately divided into equal parts and the length of each time unit changed seasonally along with the changing sunrise and sunset times. As a result, reported origin times for these earthquakes may be not accurate. In contrast, the signals of the tsunamis generated by these earthquakes were recorded by tide stations on the west coast of North America using the fixed time system in which each day is divided into $24 \mathrm{~h}$ of equal length (e.g., Bache, 1856; Satake, 2020). Although there are several problems with the observed tsunami waveforms (e.g., the hydraulic filter at the time of observation is unknown), by comparing them with calculated waveforms, they can be used to quantitatively evaluate the tsunami origin time and time difference. In fact, Kusumoto et al. (2020) estimated the origin time of the 1854 CE Ansei-Tokai tsunami to be 00:30 on 23 December by comparing the tsunami waveforms observed at stations on the west coast of North America with calculated waveforms. In this study, we first estimated the origin time of the 1854 CE Ansei-Nankai tsunami by comparing observed and simulated waveforms. Then, we calculated the time difference between the $1854 \mathrm{CE}$ Ansei-Tokai and Ansei-Nankai earthquakes by using our estimated origin time for the Ansei-Nankai tsunami and the origin estimated by Kusumoto et al. (2020) for the Ansei-Tokai tsunami and compared the result with historical descriptions of the two earthquakes and tsunamis. 


\section{Observations of the 1854 CE Ansei-Tokai and Ansei-Nankai Earthquakes} 1977). According to this report, strong shaking occurred at 08:20 local time on 23 December and again

\subsection{Historical materials}

The 1854 CE Ansei-Tokai and Ansei-Nankai earthquakes and tsunamis are summarized in Historical Documents on Earthquakes in Japan, New Collection. This is a catalog containing historical documents with many descriptions of these events. All materials for the Ansei-Tokai and AnseiNankai earthquakes use the seasonal timekeeping system in use at the time, and it is very difficult to convert descriptions from different prefectures using that timekeeping system to the local time system because sunrise and sunset times differed depending on location. Therefore, we focused on historical materials from Wakayama Prefecture, which is the regional boundary between the Ansei-Tokai and Ansei-Nankai earthquake epicenters (Earthquake Research Institute of the University of Tokyo, 1987, 1989, 1994; Usami, 2008, 2012). At the time of the earthquake, sunrise and sunset in Wakayama Prefecture occurred at 07:03 and 16:56 local time, respectively (National Astronomical Observatory of Japan, 1994). Using these times, we converted the time descriptions in the historical materials to local time. Here, we focus on three reliable contemporary sources from Wakayama Prefecture.

"Kotoki”, a report written in Japanese by Mr. Iwateya Heibei, a Japanese lacquerware worker who lived in Fukagawa-Kuroe city in the western part of the prefecture, is one of the most reliable contemporary documents for the Ansei-Tokai and Ansei-Nankai earthquakes (Yanagikawa, 

earthquake and repeated waves struck Fukagawa-Kuroe city, with the third wave being the largest. earthquakes can be estimated as approximately $32 \mathrm{~h}$. Another contemporary description is "Knowledge for Large Earthquake and Tsunami", an inscription on a monument erected in 1856 CE by Saint Zencho (Syoku), a priest of the Jinsen Temple who lived in Yuasa city in the western part of the prefecture (e.g., Hatori, 1980; Ishibashi et al., 2017). According to this monument, large earthquakes occurred at 10:10 local time on 23 December and at 15:40 local time on 24 December. A sudden rise and fall of the tide occurred on 23 December that caused no damage, but on 24 December, a large tsunami destroyed houses, ships, and warehouses and caused catastrophic damage to the entire settlement. On the basis of this description, the time difference between the Ansei-Tokai and Ansei-Nankai earthquakes can be inferred to be about $30 \mathrm{~h}$. Koza city in the southern part of the prefecture, is also a reliable contemporary document for the Ansei-Tokai and Ansei-Nankai earthquakes (e.g., Hamahata, 1977; Imai et al., 2017). According to this diary, strong shaking occurred at 10:10 LT on 23 December and 15:40 local time on 24 December. The Ansei-Tokai tsunami arrived immediately, but was not high. The Ansei-Nankai tsunami repeatedly struck, and the second wave was the highest. On the basis of this account, the time 


\subsection{Instrumental observations}

118 In 1853, tide gauge stations were installed at three sites on the west coast of the United States:

119 Astoria, Oregon, and San Francisco and San Diego, California (U.S. Coastal Survey, 1855, Fig. 1).

120 These stations used a mechanical clock to record accurate times of high and low tides. Between 23

121 and 25 December $1854 \mathrm{CE}$, rapid rises and falls of seawater were observed at these tide gauge stations.

122 Two years later, these abnormal seawater rises and falls were recognized as the 1854 CE Ansei-Tokai

123 and Ansei-Nankai tsunamis, after they had traversed the Pacific Ocean (e.g., Bache, 1856; Omori,

124 1913).

125 In this study, we used only the tsunami signals recorded at the tide gauge stations in San Francisco

126 and San Diego because the tsunami signal observed at the Astoria tide gauge station was considered

127 too ambiguous to use. The high noise level was possibly caused by storm surges or the tsunami; a

128 sketch of the Pacific Northwest coast about $55 \mathrm{~km}$ north of Astoria published in 1857 shows flooding 

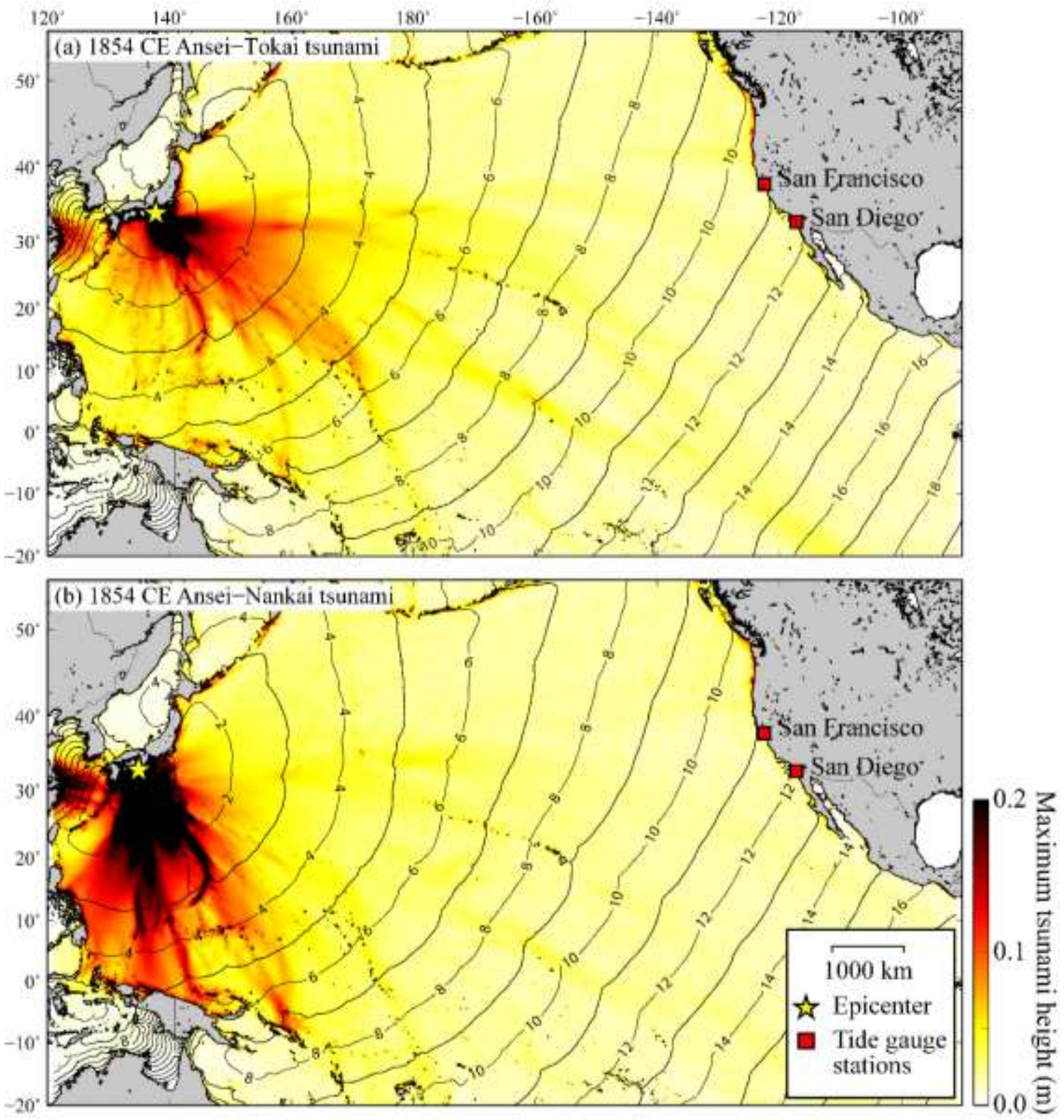

Fig. 1 Distributions of maximum tsunami heights and tsunami travel times of the 1854 CE (a) Ansei- 


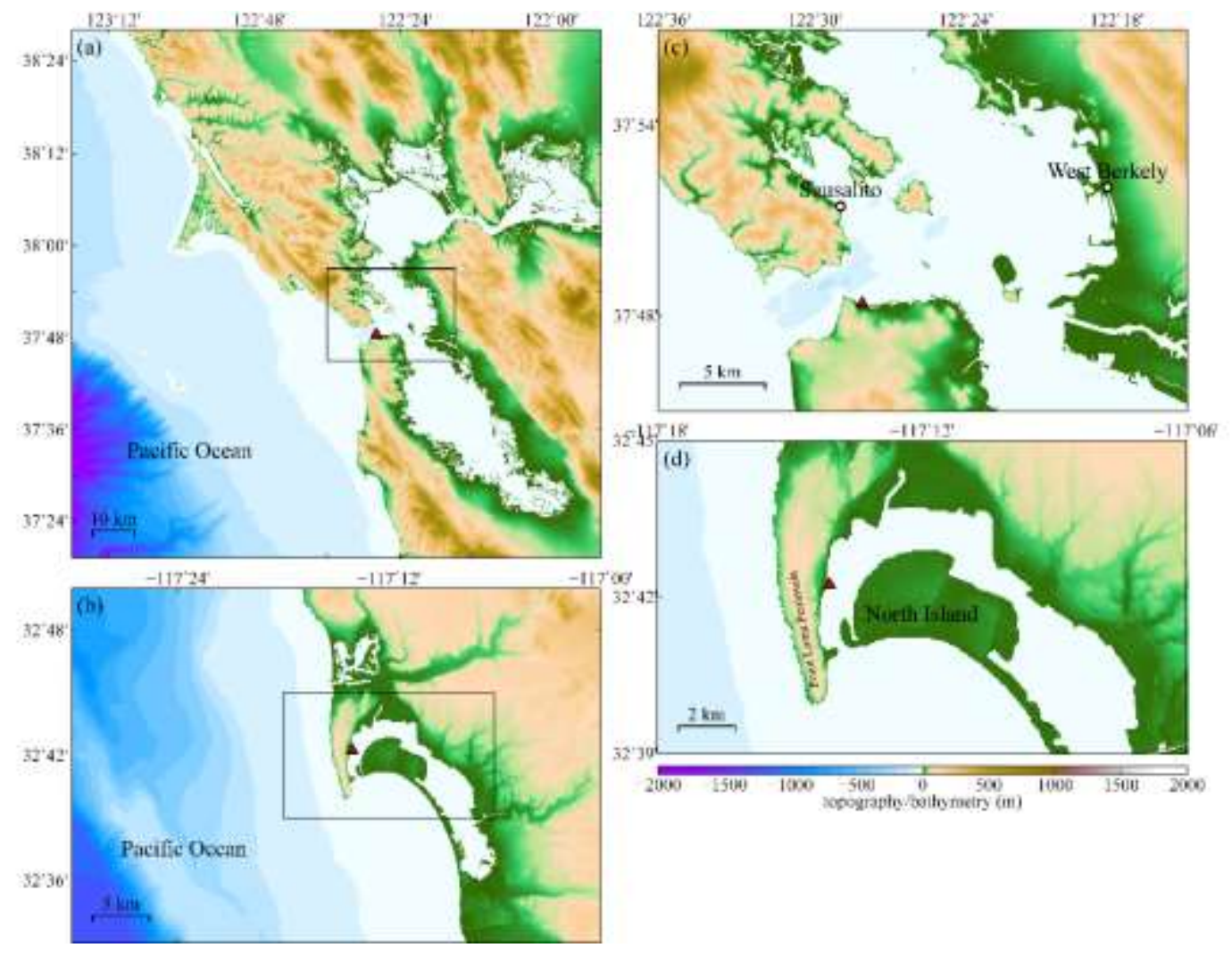

137 Fig. 2 Topography and bathymetry around the (a, c) San Francisco and (b, d) San Diego tide gauge stations. These data were manually reproduced based on old maps, and coastal structures were manually removed by referring to old maps. Red triangles show the locations of the tide gauge stations in $1854 \mathrm{CE}$.

\section{Numerical analysis}

Numerical simulation of trans-Pacific tsunami propagation was performed by using the staggered leap-frog scheme in the JAGURS tsunami simulation code (e.g., Baba et al., 2017). Trans-Pacific tsunami propagation was calculated on the basis of two-dimensional non-linear dispersive wave theory 


$$
\frac{\partial M}{\partial t}+\frac{1}{R \sin \theta} \frac{\partial}{\partial \varphi}\left(\frac{M^{2}}{H+\eta}\right)+\frac{1}{R} \frac{\partial}{\partial \theta}\left(\frac{M N}{H+\eta}\right)
$$

$$
=-\frac{g(H+\eta)}{R \sin \theta} \frac{\partial h}{\partial \varphi}-f N-\frac{g n^{2}}{(H+\eta)^{7 / 3}} M \sqrt{M^{2}+N^{2}}
$$$$
+\frac{H^{2}}{3 R \sin \theta} \frac{\partial}{\partial \varphi}\left[\frac{1}{R \sin \theta}\left(\frac{\partial^{2} M}{\partial \varphi \partial t}+\frac{\partial^{2}(N \sin \theta)}{\partial \theta \partial t}\right)\right]
$$

$$
=-\frac{g(H+\eta)}{R} \frac{\partial h}{\partial \theta}+f M-\frac{g n^{2}}{(H+\eta)^{7 / 3}} N \sqrt{M^{2}+N^{2}}
$$

$$
+\frac{H^{2}}{3 R} \frac{\partial}{\partial \theta}\left[\frac{1}{R \sin \theta}\left(\frac{\partial^{2} M}{\partial \varphi \partial t}+\frac{\partial^{2}(N \sin \theta)}{\partial \theta \partial t}\right)\right]
$$

where $M$ and $N$ are the discharge fluxes in the longitudinal $(\varphi)$ and co-latitudinal $(\theta)$ directions, the radius of the Earth, $f$ is the Coriolis parameter, and $n$ is Manning's roughness coefficient. The continuity equation is:

$\frac{\partial \eta}{\partial t}=-\frac{1}{R \sin \theta}\left[\frac{\partial M}{\partial \varphi}+\frac{\partial(N \sin \theta)}{\partial \theta}\right]$

Trans-Pacific tsunamis exhibit a phase delay owing to the elasticity of the Earth and the vertical 
where $\boldsymbol{r}$ denotes a position on the Earth's surface with the point mass located at $\boldsymbol{r}^{\prime}, P_{n}$ refers to Earth, and $h_{n}^{\prime}$ is the loading Love number of angular order $n$.

(Kusumoto et al., 2020). The effects on the observed tsunami waveform of filtering due to the structure

of the water pipe at the tide gauge station at the time of the earthquake and changes in the hydraulic response are unknown, and there is no information available that allows them to be estimated.

Therefore, we extracted the high-energy period band from the amplitude spectrum of the observed waveforms as follows. First, the amplitudes were normalized by the maximum amplitude in the time window covered by the simulation. Next, the bandpass filter cut-off period was determined from the amplitude spectrum of the observed waveforms. The tidal components were removed by applying a high-pass filter with a cut-off period of $128 \mathrm{~min}$. Figure 4 shows the resulting amplitude spectrum. The maximum energy was observed at periods of 30-80 min, and when the period was $16 \mathrm{~min}$, the energy level was approximately $1 / 10$ of the maximum. Therefore, the cut-off period of the low-pass original recording. used the An'naka model, which was inferred from tsunami inundation and run-up heights (Table 1; 
184 was computed for the source model (e.g., Okada, 1985; Tanioka and Satake, 1996), and the Kajiura

185 filter was applied to convert crustal displacement to initial sea-surface displacement (Kajiura, 1963).

186 To numerically model the tsunami, we adopted a nested grid system in which the nested grids included

$187162,54,18,6$, and 2 arc-seconds in the spherical coordinate system. To produce the nested grid system,

188 the General Bathymetric Chart of the Oceans

189 (https://www.gebco.net/data and products/gridded bathymetry_data/gebco_2021/) and high-

190 resolution (1/3 arc-second) coastal digital elevation and depth models from the U.S. National Oceanic

191 and Atmospheric Administration were combined and resampled. Coastal structures constructed after

$1921854 \mathrm{CE}$ were manually removed by referring to old topographic maps. A time step of $0.5 \mathrm{~s}$ was used

193 in our simulations to ensure computational stability of the finite-difference algorithm with the finest

194 grid.

The first signal of the Ansei-Nankai tsunami was obscured by later waves of the Ansei-Tokai

tsunami. Therefore, we conducted a wavelet analysis of the observed waveforms to judge the arrival

time of the Ansei-Nankai tsunami by applying Wavelet Analysis Package Software developed by

Torrence and Compo (1998). We used the Morlet function with a scaling parameter as the wavelet

mother function.

To compare the simulated and observed waveforms, we used the normalized root mean square

(NRMS) and the NRMS misfit values calculated as follows: 


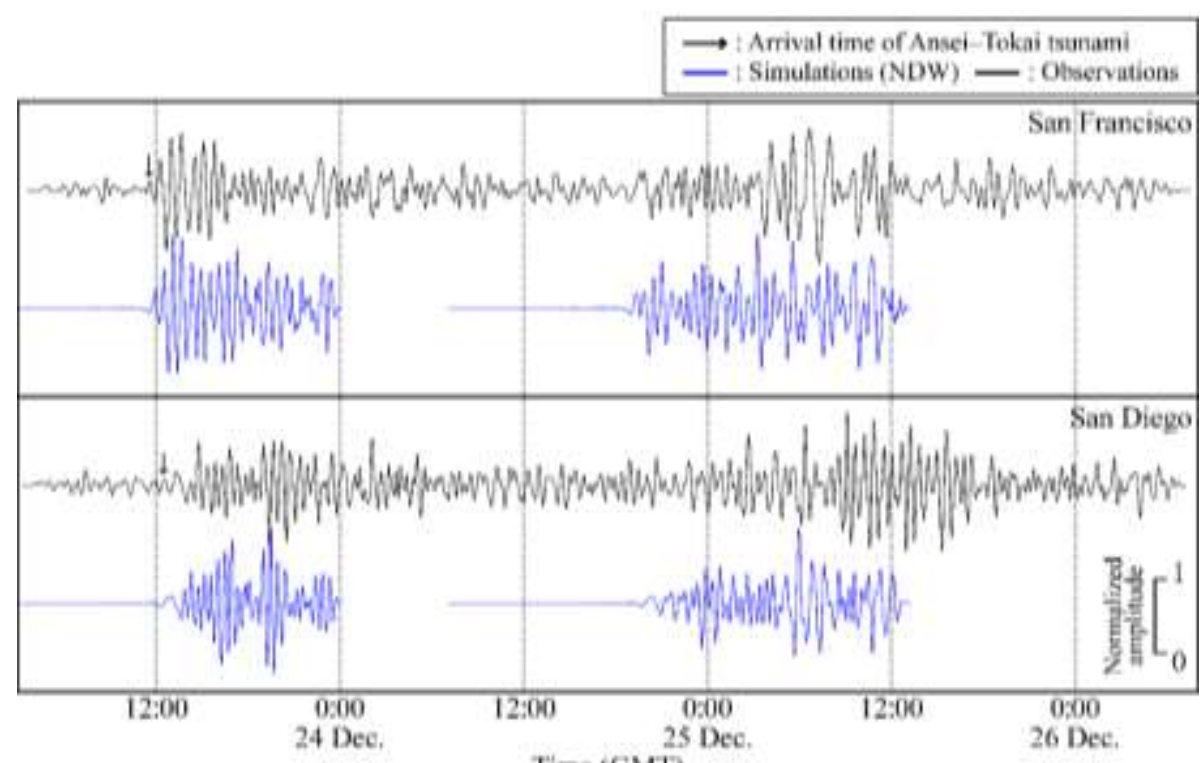

211 Fig. 3 Comparison of observations and non-linear dispersive wave (NDW) simulation results for the

212 San Francisco and San Diego tide gauge stations. Black and blue curves show the observed and

213 simulated waveforms, respectively, after application of low and high bandpass filters with cut-off 


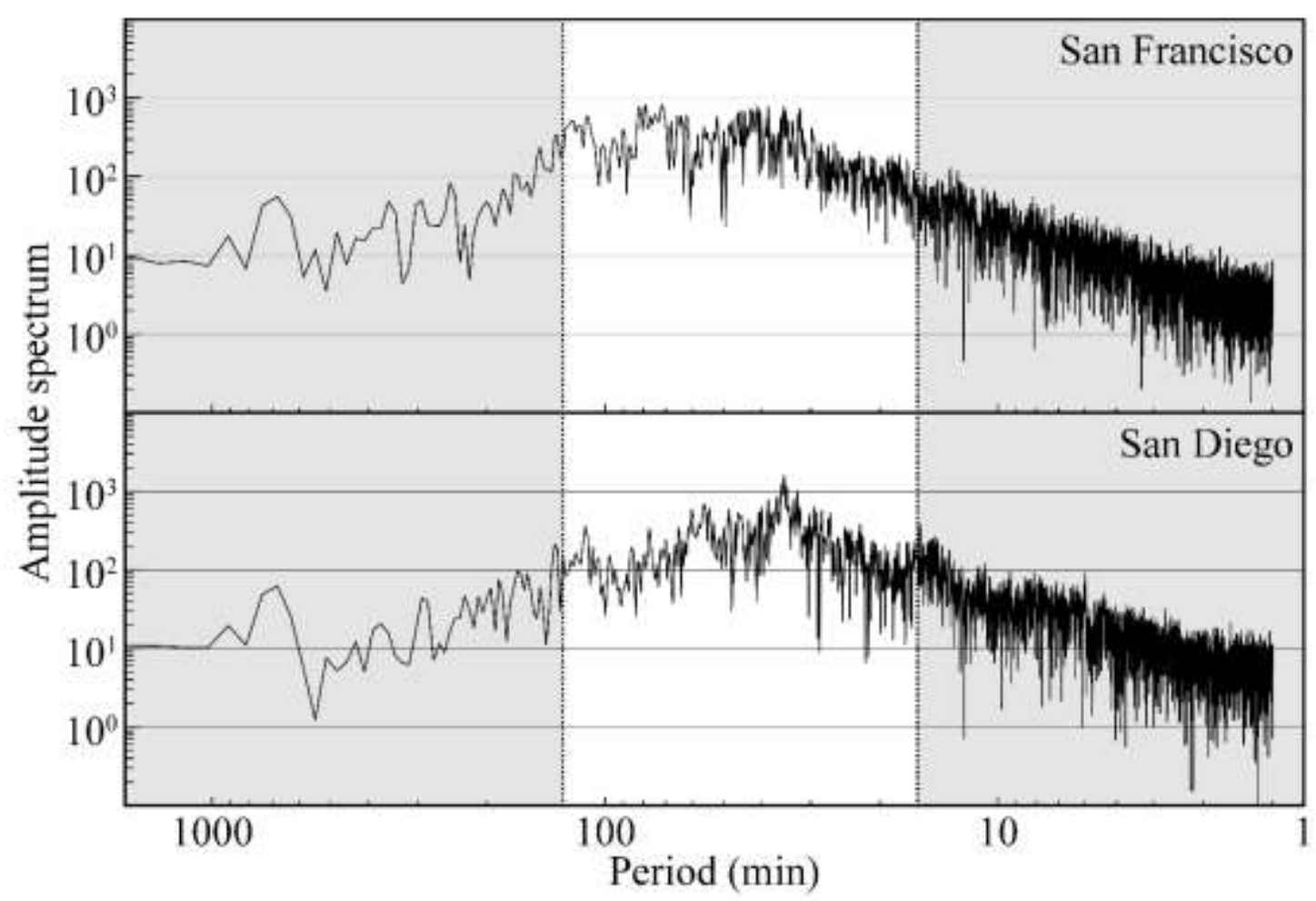

216

217 Fig. 4 Amplitude spectrums of the observed waveforms at the San Francisco and San Diego tide gauge

218 stations. Portions of the energy band removed by application of the low and high bandpass filters (cut-

219 off periods of 16 and $128 \mathrm{~min}$, respectively) are shaded gray.

222 Table 1 Fault parameters of the 1854 CE Ansei-Tokai and Ansei-Nankai earthquakes 


\begin{tabular}{lccccccccc}
\hline Subfault & Length & Width & Depth & Strike & Dip & Rake & Slip & Latitude & Longitude \\
No. & $(\mathrm{km})$ & $(\mathrm{km})$ & $(\mathrm{km})$ & $(\mathrm{deg})$ & $(\mathrm{deg})$ & $(\mathrm{deg})$ & $(\mathrm{m})$ & $(\mathrm{deg} \mathrm{N})$ & $(\mathrm{deg}$ E) \\
\hline $\mathrm{N} 1$ & 120 & 50 & 6.4 & 193 & 20 & 71 & 5.27 & 35.120 & 138.706 \\
$\mathrm{~N} 2$ & 205 & 100 & 4.1 & 246 & 10 & 113 & 5.50 & 33.823 & 138.235 \\
$\mathrm{~N} 3$ & 155 & 100 & 7.8 & 251 & 12 & 113 & 4.80 & 33.006 & 136.074 \\
$\mathrm{~N} 4$ & 125 & 120 & 10.1 & 250 & 8 & 113 & 8.70 & 32.614 & 134.481 \\
\hline
\end{tabular}

\section{Results and discussion}

\subsection{Characteristics of the tsunami signals} those of the $1854 \mathrm{CE}$ Ansei-Nankai earthquake were obscured by later waves of the Ansei-Tokai tsunami. Comparing the initial observed waveforms of the Ansei-Tokai and Ansei-Nankai tsunamis 

gauge station, the dominant period had an upper limit of about $70 \mathrm{~min}$.
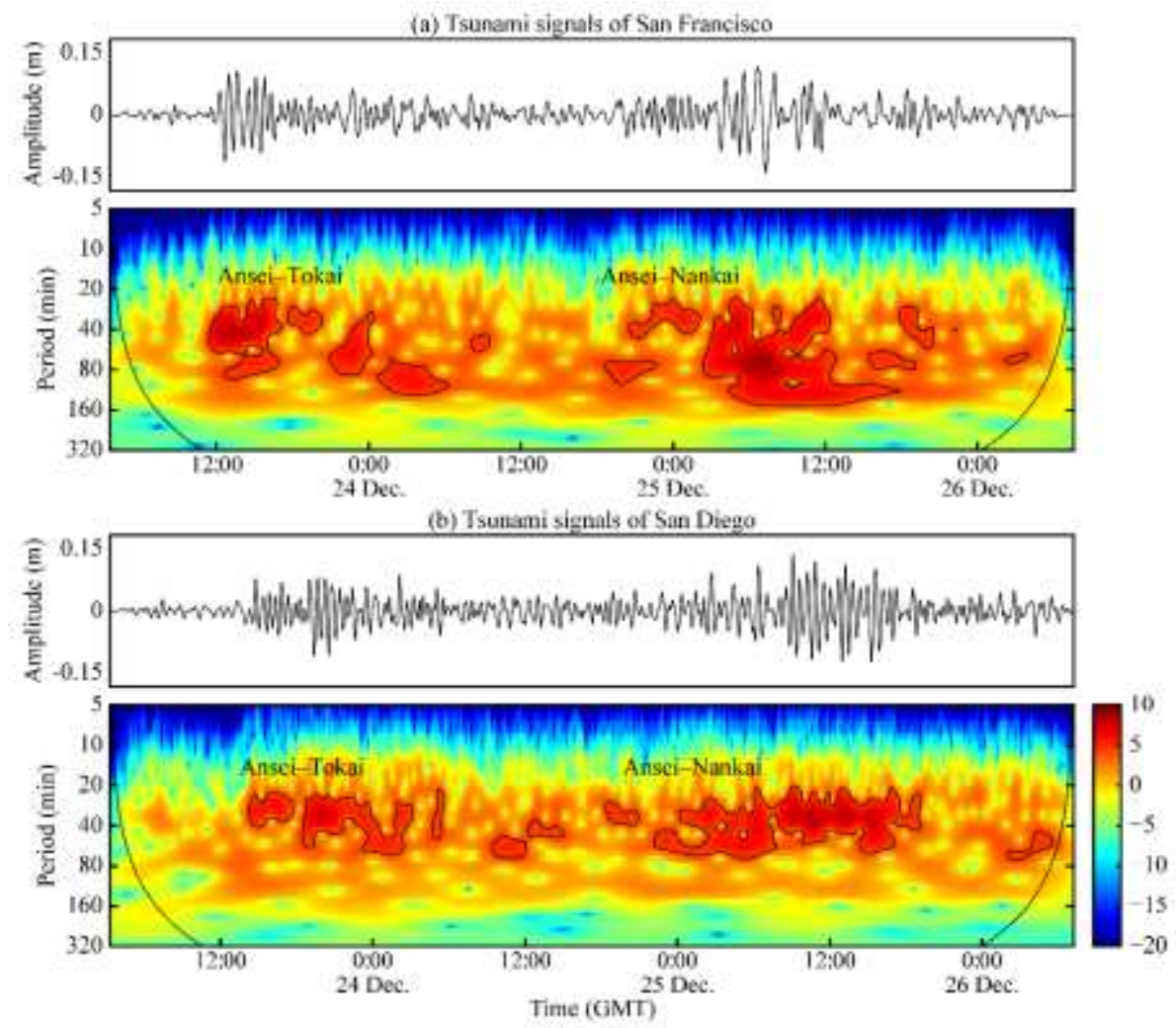
247 Fig. 5 Wavelet analysis results for the tsunami signals recorded at the (a) San Francisco and (b) San

248 Diego tide gauge stations. The amplitudes have not been normalized. Contour lines show the 95\%

249 confidence interval.

250

251

\subsection{Origin times of the 1854 CE Ansei-Nankai tsunamis}

252

The simulated tsunami waves reached the west coast of North America about 11-12 $\mathrm{h}$ after

253

the earthquake (Fig. 1). When the observed waveforms were compared with those simulated by

254

assuming that the 1854 CE Ansei-Nankai tsunami originated at 07:00 GMT on 24 December, the

255

observed waveforms lagged behind the simulated waveforms by several tens of minutes (Fig. 7).

256

Figure 6 shows the NRMS and the NRMS misfit between the simulated waveforms and those observed

257

at the San Francisco and San Diego tide gauge stations. The minimum NRMS misfit value was

258

calculated when the simulated waveforms were shifted by $0.4 \mathrm{~h}$. Because the simulated waveforms

after shifting roughly matched the observed waveforms (Fig. 7), we estimated the origin time of the

1854 Ansei-Nankai tsunami to be 07:24 GMT on 24 December.

4.3 Time difference between the Ansei-Tokai and Ansei-Nankai earthquakes

Kusumoto et al. (2020) compared simulated and observed waveforms recorded at San

Francisco and San Diego tide gauge stations and concluded that the origin time of the 1854 CE Ansei- 


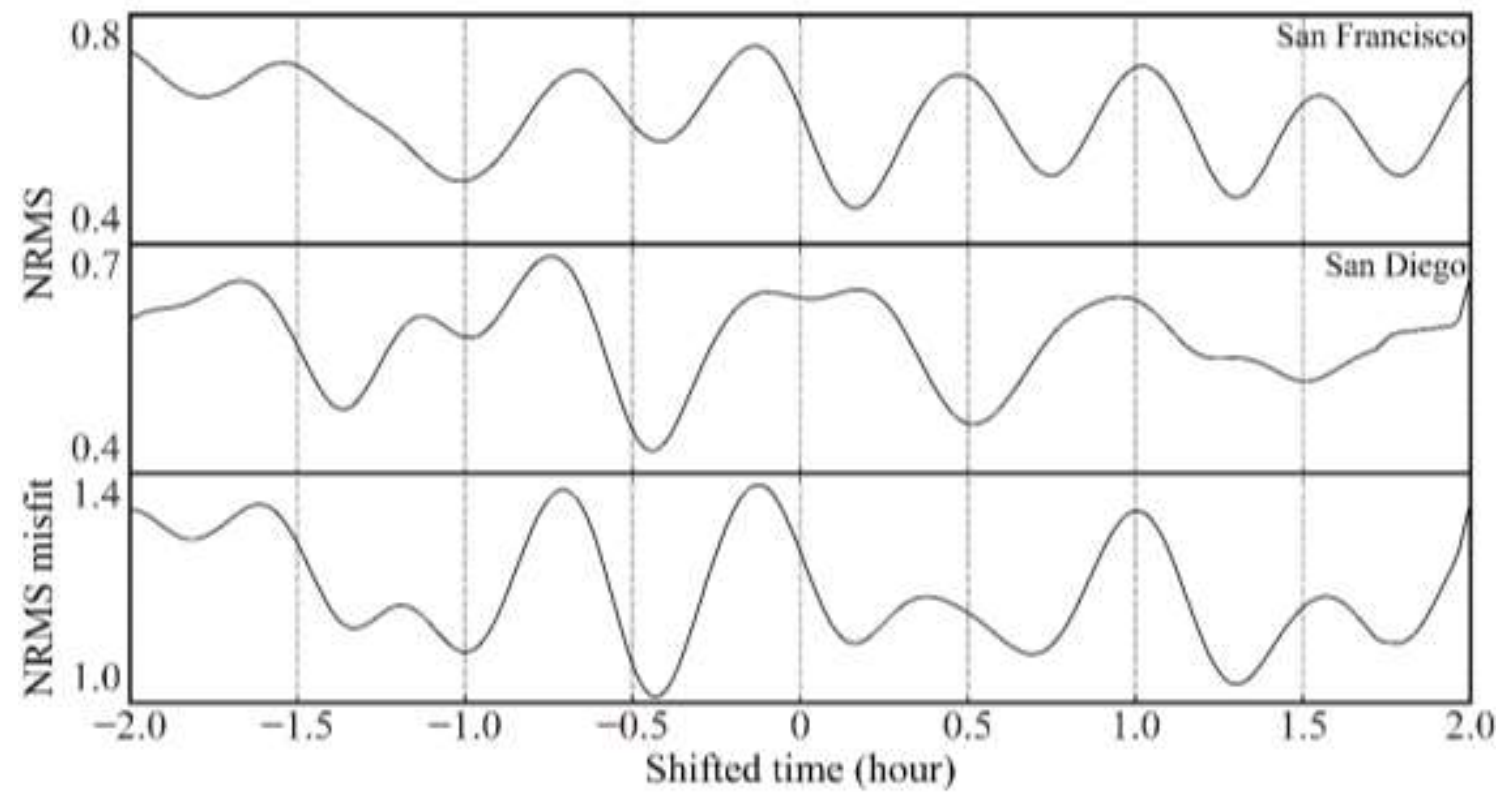

Fig. 6 Normalized root mean square (NRMS) and NRMS misfit between observed and simulated

(a) San Francisco

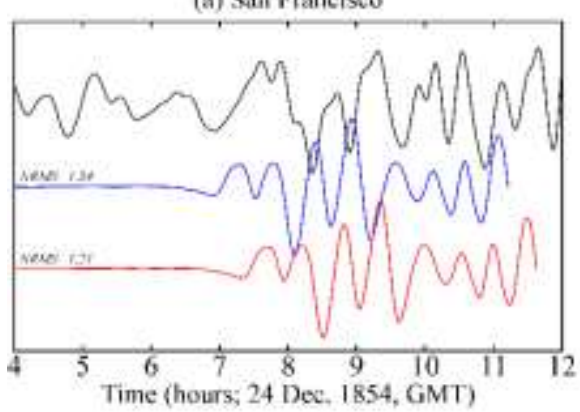

(b) San Dicgo

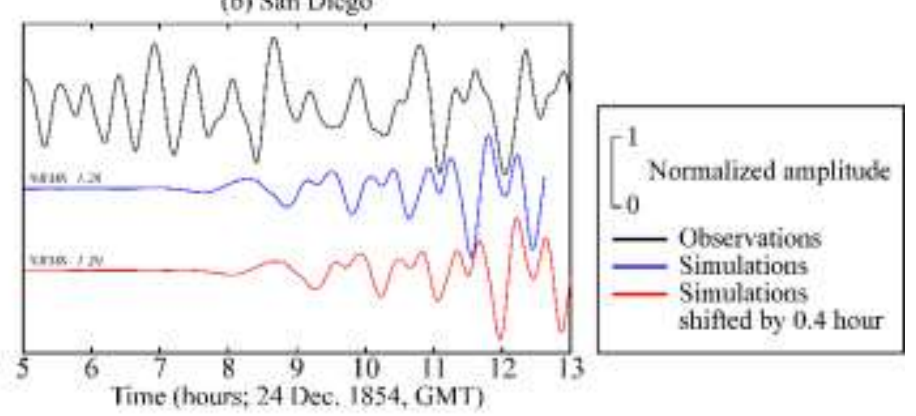

Fig. 7 Comparison of observed and simulated waveforms of the 1854 CE Ansei-Nankai tsunami 

show the observations, simulations, and simulations shifted by $0.4 \mathrm{~h}$, respectively.

\subsection{Comparison with descriptions in historical documents}

According to historical descriptions in Wakayama Prefecture documents, the 1854 CE Ansei-

Nankai earthquake occurred at about 16:00 local time on 24 December. Local time in Wakayama

Council, 2005; Matsu'ura, 2017). Thus, the resolution of the seasonal timekeeping system used in

\section{Conclusions}


between the Ansei-Tokai and Ansei-Nankai earthquakes from tidal records of the San Francisco and

Tokai tsunami to be 00:30 GMT on 23 December; thus we estimated the time difference between the 
Availability of data and materials

317 information of Kusumoto et al. (2020) (available at https://doi.org/10.1785/0220200068).

318

319

Competing interests

320 The authors declare that they have no competing interests.

321

$322 \quad$ Funding

This work was supported by the Research Project for Disaster Prevention on the great

Earthquakes along the Nankai trough

325

326

Authors' contributions

327

$\mathrm{KI}$ and $\mathrm{TH}$ contributed to the interpretation of the data. All authors read and approved the

final manuscript.

Acknowledgement station. 
335 Allgeyer S, Cummins P (2014) Numerical tsunami simulation including elastic loading and seawater density stratification, Geophys. Res. Lett., 41, pp. 2368-2375, doi:10.1002/2014GL059348.

Ando M (1975) Source mechanisms and tectonic significance of historical earthquakes https://doi.org/10.1016/0040-1951(75)90102-X

An'naka T, Inagaki K, Tanaka H, Yanagisawa K, (2003) Characteristics of great earthquakes along the Nankai trough based on numerical tsunami simulation, J. Earthquake Eng., 27, article 307.

Baba T, Allgeyer S, Hossen J, Cummins PR, Tsushima H, Imai K, Ymashita K, Kato T, (2017) Accurate numerical simulation of the far-field tsunami caused by the 2011

Bache AD (1856) Notice of earthquake waves on the western coast of the United States, 
352 for long-period ground motion evaluation, Attachment 2 Appendix 3 (in Japanese)

$353 \quad$ https://www.kenken.go.jp/japanese/contents/topics/lpe/

354 Cabinet Office Committee for Modeling a Nankai Trough Megaquake (2015) Long355 period ground motion due to a huge earthquake along the Nankai Trough (in Japanese) http://www.bousai.go.jp/jishin/nankai/nankaitrough_report.html

357 Central Disaster Management Council (2005) Business Continuity Guideline, Cabinet 358 $\underline{\text { nankai jishin/index.html }}$

Cooper JG (1853-1854) NOTE BOOK, Transcribed and Reviewed by Digital Volunteers Extracted April-08-2020.

Earthquake Research Institute (1987) New collection of historical materials on earthquakes in Japan, vol S5-5-1\&2. ERI, Tokyo, pp 2528 (in Japanese)

Earthquake Research Institute (1989) New collection of historical materials on earthquakes in Japan, Suppl S. ERI, Tokyo, pp 992 (in Japanese)

Earthquake Research Institute (1994) New collection of historical materials on earthquakes in Japan, Add. Suppl. S. ERI, Tokyo, pp 1228 (in Japanese)

Fujiwara O, Goto K, Ando R, Garrett E, (2020) Paleotsunami research along the Nankai 
Garrett E, Fujiwara O, Garrett P, Heyvaert VMA, Shishikura M, Yokoyama Y, Hubertgeological evidence for Holocene earthquakes and tsunamis along the Nankai-Suruga Trough, Japan.,

Earth

Sci.

Rev.,

159,

$337-357$. http://dx.doi.org/10.1016/j.earscirev.2016.06.011.

Hamahata E (1977) Continued historical materials of the Kumano city, pp. 203-208

Hatori T (1980) Field Investigation of the Nankaido Tsunamis in 1707 and 1854 along pp.505-535

(in Japanese)

https://repository.dl.itc.u-

Honda K, Terada T, Yoshida Y, Isitani D (1908) An investigation on the secondary undulations of oceanic tides, J. College Sci.,Imper. Univ. Tokyo, 108 pp.

Imai K, Ishibashi M, Namegaya Y, Ebina Y (2017) Field survey for tsunami trace height 
Ishibashi K (2004) Status of historical seismology in Japan, Ann. Geophys., 47(2-3), pp. 339-368, https://doi.org/10.4401/ag-3305

Ishibashi M, Maeda M, Imai K, Takahashi N, Baba T, Obayashi R, Inazumi T, (2017) The tsunami monument distribution along the coast of Wakayama Prefecture, Research Report of Tsunami Engineering, 33, pp. 109-120.

Kajiura K (1963) The leading wave of a tsunami, Bull. Earthquake Res. Inst., Univ. Tokyo, 41, pp. 535-571.

Kusumoto S, Imai K, Obayashi R, Hori T, Takahashi N, Ho TC, Uno K, Tanioka Y, Satake K (2020) Origin Time of the 1854 Ansei-Tokai Tsunami Estimated from Tide Gauge Records on the West Coast of North America, Seismological Research Letters, 91 (5), pp. 2624-2630, https://doi.org/10.1785/0220200068

Matsu'ura R (2017) Earthquake Forecasting and the Large-Scale Earthquake Countermeasures Act, Monogr. Seismol. Soc. Jpn., 5, pp. 15-19 (in Japanese).

National Astronomical Observatory of Japan (1994) Koyomi Station, https://eco.mtk.nao.ac.jp/cgi-bin/koyomi/koyomix_en.cgi (Accessed 30 June 2021)

Okada Y (1985) Surface displacement due to shear and tensile faults in a half-space, Bull. Seismol. Soc. Am., 75 (4), pp. 1135-1154.

Omori F (1913) An account of the destructive earthquakes in Japan, Publ. Eq. Inv. Com., 68B, 1-179 (in Japanese). 
409 Satake K, Heidarazadeh M, Quiroz M, Cienfuegos R (2020) History and Features of 410 Trans-oceanic Tsunamis and Implications for Paleo-tsunami Studies, Earth Sci. Rev., 202, 103112, https://doi.org/10.1016/j.earscirev.2020.103112

412 Tanioka Y, Satake K (1996) Tsunami generation by horizontal displacement of ocean 413 bottom, Geophys. Res. Lett., 23 (8), pp. 861-864.

414 Tolkova E, Tanaka H, Roh M (2015) Tsunami Observations in Rivers from a Perspective 415 of tsunami interaction with tide and riverine flow, Pure Appl. Geophys. 172, pp. 953416968.

417 Torrence C, Compo GP (1998) A practical guide to wavelet analysis, Bull. Am. Meteorol. $418 \quad$ Soc., 79, pp. 61-78.

419 U. S. Coast Survey (1855) Annual Report of the Superintendent of the Coast Survey, $420 \quad$ National Oceanic and Atmosphere Administration, $288 \mathrm{pp}$.

421 Usami T (2003) Materials for comprehensive list of Japanese destructive earthquakes 422 [Latest Edition] [416]-2001. Univ Tokyo Press, Tokyo, p 605 (in Japanese)

Usami T (2008) Addendum of historical documents on earthquakes in Japan, 4-1\&2, T. Tokyo, Usami, pp. 1874 (in Japanese)

425 Usami T (2012) Addendum of historical documents on earthquakes in Japan, 5-1\&2, T. Usami, Tokyo, pp 1526 (in Japanese)

427 Watada S, Kusumoto S, Satake K (2014) Traveltime delay and initial phase reversal of 

Earth, 119, doi:10.1002/2013JB010841.

430 Yanagikawa K (1977) The Takanami Records by Iwateya Heibei in Kuroe, Kainan-shishi, 4313 3, pp. 33-37 (in Japanese). 